\title{
Screening to Identify Commonly Used Chinese Herbs That Affect ERBB2 and ESR1 Gene Expression Using the Human Breast Cancer MCF-7 Cell Line
}

\author{
Jen-Hwey Chiu, ${ }^{1,2,3}$ Chun-Ju Chang, ${ }^{4}$ Jing-Chong Wu, ${ }^{5}$ Hui-Ju Liu, ${ }^{1}$ \\ Che-Sheng Wen, ${ }^{6}$ Chung-Hua Hsu, ${ }^{1}$ Jiun-Liang Chen, ${ }^{7,8}$ Ling-Ming Tseng, ${ }^{2,9}$ \\ Wei-Shone Chen, ${ }^{10,11}$ and Yi-Ming Shyr ${ }^{2}$ \\ ${ }^{1}$ Institute of Traditional Medicine, School of Medicine, National Yang-Ming University, Taipei 112, Taiwan \\ ${ }^{2}$ Division of General Surgery, Department of Surgery, Taipei Veterans General Hospital, Taipei 112, Taiwan \\ ${ }^{3}$ Division of General Surgery, Department of Surgery, Cheng Hsin General Hospital, Taipei 112, Taiwan \\ ${ }^{4}$ Department of Food Science, National Taiwan Ocean University, Keelung 202, Taiwan \\ ${ }^{5}$ Center for Traditional Chinese Medicine, Kaohsiung Veterans General Hospital, Kaohsiung 81362, Taiwan \\ ${ }^{6}$ Department of Orthopedics, Cheng Hsin General Hospital, Taipei 112, Taiwan \\ ${ }^{7}$ School of Traditional Chinese Medicine, Chang Gung University, Taoyuan 333, Taiwan \\ ${ }^{8}$ Center for Traditional Chinese Medicine, Chang Gung Memorial Hospital, Taoyuan 333, Taiwan \\ ${ }^{9}$ School of Medicine, National Yang-Ming University, Taipei 112, Taiwan \\ ${ }^{10}$ Division of Colorectal Surgery, Department of Surgery, Taipei Veterans General Hospital, Taipei 112, Taiwan \\ ${ }^{11}$ Experimental Surgery of the Department of Surgery, Taipei Veterans General Hospital, Taipei 112, Taiwan
}

Correspondence should be addressed to Ling-Ming Tseng; lmtseng@vghtpe.gov.tw

Received 20 February 2014; Revised 18 April 2014; Accepted 30 April 2014; Published 27 May 2014

Academic Editor: Pau-Chung Chen

Copyright (C) 2014 Jen-Hwey Chiu et al. This is an open access article distributed under the Creative Commons Attribution License, which permits unrestricted use, distribution, and reproduction in any medium, provided the original work is properly cited.

\begin{abstract}
Aim. Our aim the was to screen the commonly used Chinese herbs in order to detect changes in ERBB2 and ESR1 gene expression using MCF-7 cells. Methods. Using the MCF-7 human breast cancer cell line, cell cytotoxicity and proliferation were evaluated by MTT and trypan blue exclusion assays, respectively. A luciferase reporter assay was established by transient transfecting MCF-7 cells with plasmids containing either the ERBB2 or the ESR1 promoter region linked to the luciferase gene. Chinese herbal extracts were used to treat the cells at $24 \mathrm{~h}$ after transfection, followed by measurement of their luciferase activity. The screening results were verified by Western blotting to measure HER 2 and ER $\alpha$ protein expression. Results. At concentrations that induced little cytotoxicity, thirteen single herbal extracts and five compound recipes were found to increase either ERBB2 or ESR1 luciferase activity. By Western blotting, Si-Wu-Tang, Kuan-Shin-Yin, and Suan-Tsao-Ren-Tang were found to increase either HER2 or ER $\alpha$ protein expression. In addition, Ligusticum chuanxiong was shown to have a great effect on ERBB2 gene expression and synergistically with estrogen to stimulate MCF-7 cell growth. Conclusion. Our results provide important information that should affect clinical treatment strategies among breast cancer patients who are receiving hormonal or targeted therapies.
\end{abstract}

\section{Introduction}

Breast cancer is the most common invasive female cancer worldwide as well as in Taiwan $[1,2]$. Due to its diverse morphological features, the pathological classification of breast cancers has insufficient prognostic and predictive power. Recently, molecular analysis of breast cancer tissue using immunohistochemistry, measurement of proliferative capacity, and analysis of gene expression profiles has provided a number of feasible treatment strategies that correlate well with clinical outcome [3-5].

There is a consensus that the estrogen and/or progesterone receptor status of breast cancers is an important prognosis factor when assessing the probable response to 
adjuvant hormonal therapy $[6,7]$. Hormonal therapy using tamoxifen over a five-year period has been shown to result in a significant reduction in the annual breast cancer death rate of 34\% [8]. In addition, using antibody against the HER2/neu receptor (trastuzumab) or/and the use of its dimerisation inhibitor (pertuzumab) remain important adjuvant target therapies after surgery $[9,10]$. Nonetheless, information concerning possible interactions between herbs and drug targets such as the ER receptor and HER2/neu remains to be elucidated.

Accumulating evidence suggests that hormone therapy has a number of adverse effects among breast cancer patients, such as insomnia, hot flushes, and cancer-related fatigue; for example, hot flushes occur in up to $80 \%$ of women who are receiving tamoxifen [11-13]. It is generally accepted that the use of complementary and alternative medicines (CAMs) has increased among oncology patients, with the prevalence being as high as $70 \%$ to $80 \%$ of patients in non-Asian areas [14, 15 ] and around $36 \%$ to $40 \%$ in Taiwan. It is worth noting that traditional Chinese medicine (TCM), by definition, cannot be defined as CAMs in oriental countries. In Taiwan, more than one-third of breast cancer patients have used TCM and more than $80 \%$ of TCM users chose Chinese herbal products as their means of adjuvant management of breast cancer [16]. Unfortunately, many of these patients who use TCM herbal remedies are not aware of their potential adverse effects, namely, the possibility of herb-drug interactions that might counteract the effects of the hormonal therapy or targeted therapy [17].

For thousands of years, herbal medicines have been an important treatment strategy in traditional Chinese medicine and have been widely used to maintain human health in oriental countries. Epidemiological evidence has shown that many herbal remedies, such as Jia-Wei-Xiao-Yao-San, are commonly used to alleviate severe symptoms in breast cancer patients who are receiving hormonal therapy or targeted therapies [18]. Our previous in vitro [17] and in vivo studies using MCF-7 breast cancer cells have shown that Si-WuTang (SWT) is able to reverse the antiproliferative effects induced by tamoxifen, including tumor weight, tumor volume, increased $\mathrm{ER} \alpha$ expression, and $\mathrm{N}$-cadherin expression, when the tamoxifen + SWT-treated group is compared to the tamoxifen-treated group [19]. However, information on whether other commonly used Chinese herbal medicines may affect ER $\alpha$ and HER2 expression in breast cancer cells is lacking. Accordingly, the aim of this study was to screen using the human breast cancer MCF-7 cell line a number of commonly used Chinese herbs, which included twenty-two single herbs and six compound recipes, in order to determine whether these herbs/recipes are able to affect ESR1 and $E R B B 2$ gene expression.

\section{Materials and Methods}

2.1. Cell Line and Cell Culture. The MCF-7 (ER+, HER2 low) cell line was obtained from the American Type Culture Collection (ATCC, Manassas, VA, USA). MCF-7 cells were maintained in DMEM supplemented with $10 \%$ fetal bovine serum
(FBS), 2 mM L-glutamine (Sigma), $1.5 \mathrm{~g} / \mathrm{L}$ sodium bicarbonate (Sigma), $0.1 \mathrm{mM}$ nonessential amino acid, $1.0 \mathrm{mM}$ sodium pyruvate (Sigma), and penicillin/streptomycin. To prevent the influence of hormones or estrogen-like compounds that may be present in conventional culture medium, the cultured cells were transferred to phenol red-free DMEM containing $5 \%$ charcoal-dextran stripped fetal bovine serum (CDFBS), nonessential amino acid, and penicillin/streptomycin 4 days before treatment. Furthermore, the cells were incubated with hormone-free medium and the water extract of the various herbal remedies in the presence of polymyxin $\mathrm{B}$ $(1 \mu \mathrm{g} / \mathrm{mL})$ to avoid the possibility of lipopolysaccharide contamination.

\subsection{Preparation of Extracts from Commonly Used Chinese} Herbs (CHEs). In this study, twenty-two commonly used Chinese single herbs are presented in Table 1 using their scientific names, which are coded from A to V. These are Astragalus membranaceus (A), Atractylodes macrocephala (B), Poria cocos (C), Glycyrrhiza uralensis (D), Agastache rugosa (E), Codonopsis pilosula (F), Zingiber officinale (G), Angelica sinensis (H), Ligusticum chuanxiong (I), Ziziphus jujuba (J), Millettia dielsiana (K), Curcuma phaeocaulis (L), Folium nelumbinis (M), Bupleurum chinense (N), Mentha piperita (O), Gardenia jasminoides (P), Paeonia suffruticosa (Q), Taraxacum mongolicum (R), Anemarrhena asphodeloides (S), Paeonia lactiflora (T), Rehmannia glutinosa (U), and Ligustrum lucidum (V). The six compound recipes are as follows, namely, Si-Wu-Tang, Jia-Wei-Xiao-Yao-San (JWXYS), Suan-Zao-Ren-Tang (SZRT) and its reduced formula Suan-Zao-Ren-Tang, K'uan-Hsin-Yin, and VGH-S4 (Table 1). The reduced formula of Suan-Zao-Ren-Tang (rSZRT) is composed of the same herbs as Suan-Zao-RenTang except for Ligusticum chuanxiong which is absent. VGH-S4, which contains Curcuma phaeocaulis, Taraxacum mongolicum, Millettia dielsiana, and Mentha piperita, is a compound recipe commonly used in Taipei Veterans General Hospital. JWXYS is composed of Radix bupleuri, Radix Angelicae sinensis, Radix Paeoniae alba, Rhizoma Atractylodis macrocephalae, Poria, Rhizoma Zingiberis preparata, Cortex Moutan, Fructus Gardeniae, Herba Menthae, and Radix Glycyrrhizae praeparata. The preparation of extracts from these Chinese medicinal herbs, denoted as CHEs (Chinese herbal extracts) followed standard procedures in order to obtain compositions similar to those used clinically. The herb materials were extracted by a good manufacturing practice (GMP) company (Sun Ten Pharmaceutical Co., Ltd.). The final preparations were stored at $-20^{\circ} \mathrm{C}$ until their use in the experiments. The quality control (QC) of the herbs was monitored by high-performance liquid chromatography (HPLC) $[17,20]$.

2.3. MTT Cytotoxicity Assay and Cell Proliferation Assay. The cytotoxic activity of the various CHEs with respect to MCF-7 cells was determined by the colorimetric assay using 3-(4,5-Dimethylthiazol-2-yl)-2,5-diphenyltetrazolium bromide (MTT). Cells were seeded $24 \mathrm{hr}$ prior to treatment in a 96 -well plate at $1 \times 10^{4}$ cells/well. After $24 \mathrm{hr}$ of attachment, 
TABLE 1: Commonly used Chinese single herbs and compound recipes in this study.

\begin{tabular}{|c|c|c|c|}
\hline Nature & Scientific name & Chinese name & Code \\
\hline \multirow{7}{*}{ Qi-supplying } & Astragalus membranaceus & huang qi & $\mathrm{A}$ \\
\hline & Atractylodes macrocephala & bai zhu & $\mathrm{B}$ \\
\hline & Poria cocos & fu ling & $\mathrm{C}$ \\
\hline & Glycyrrhiza uralensis & gan cao & $\mathrm{D}$ \\
\hline & Agastache rugosa & huo xiang & $\mathrm{E}$ \\
\hline & Codonopsis pilosula & dang shen & $\mathrm{F}$ \\
\hline & Zingiber officinale & sheng jiang & G \\
\hline \multirow{5}{*}{ Blood-regulating } & Angelica sinensis & dang gui & $\mathrm{H}$ \\
\hline & Ligusticum chuanxiong & chuan xiong & I \\
\hline & Ziziphus jujuba & suan tsao jen & $\mathrm{J}$ \\
\hline & Millettia dielsiana & ji xue teng & K \\
\hline & Curcuma phaeocaulis & e zhu & $\mathrm{L}$ \\
\hline \multirow{7}{*}{ Heat-clearing } & Folium nelumbinis & he ye & M \\
\hline & Bupleurum chinense & chai hu & $\mathrm{N}$ \\
\hline & Mentha piperita & bo he & $\mathrm{O}$ \\
\hline & Gardenia jasminoides & zhi zi & $\mathrm{P}$ \\
\hline & Paeonia suffruticosa & mu dan pi & Q \\
\hline & Taraxacum mongolicum & pu gong ying & $\mathrm{R}$ \\
\hline & Anemarrhena asphodeloides & zhi mu & $\mathrm{S}$ \\
\hline \multirow{3}{*}{ Yin-nourishing } & Paeonia lactiflora & bai shao & $\mathrm{T}$ \\
\hline & Rehmannia glutinosa & di huang & $\mathrm{U}$ \\
\hline & Ligustrum lucidum & nv zhen zi & $\mathrm{V}$ \\
\hline \multirow{6}{*}{ Compound recipes and abbreviations } & Si-Wu-Tang & SWT & \\
\hline & Jia-Wei-Xiao-Yao-San & JWXYS & \\
\hline & Suan-Zsao-Ren-Tang & SZRT & \\
\hline & Reduced formula of Suan-Zsao-Ren-Tang & r-SZRT ${ }^{*}$ & \\
\hline & K’uan-Hsin-Yin & KHY & \\
\hline & VGH-S4 & VGH-S4 & \\
\hline
\end{tabular}

Scientific name is coded by international binomial nomenclature. VGH-S4 is a compound recipe commonly used in Taipei Veterans General Hospital.

${ }^{*}$ Reduced formula of Suan-Zsao-Ren-Tang (r-SZRT) is composed of those materials in Suan-Zsao-Ren-Tang except for Ligusticum chuanxiong which is absent.

cells were treated with various doses $(0 \sim 10 \mu \mathrm{g} / \mathrm{L})$ of individual CHEs for 48 and $72 \mathrm{hr}$. Each CHE was dissolved in phosphate buffered saline (PBS) $\mathrm{pH}$ 7.4. And PBS alone was used as the vehicle control. For MTT assay, both the treated and untreated cells were incubated with $100 \mu \mathrm{L}$ MTT (tetrazolium compounds) for $4 \mathrm{~h}$ and lysed with $100 \mu \mathrm{L}$ DMSO, and the optic density was read using an ELISA reader at a wavelength of $570 \mathrm{~nm}$. In addition, where needed, cell proliferation was determined by the trypan blue exclusion method.

2.4. Luciferase Reporter Assays Used to Measure ERBB2 and ESR1 Gene Expression Levels. To investigate the effects of commonly used CHEs on ERBB2 and ESR1 gene expression, the luciferase reporter vector pGL2, containing the human HER2 gene (ERBB2 luciferase: RDB number 2839, RIKEN BioResource Center, Ibaraki, Japan) or the luciferase reporter vector pGL4 containing the human $\mathrm{ER} \alpha$ gene (ESR1 luciferase: RDB number 7528) promoters were constructed and transiently transfected into MCF-7 cells. The transfection procedure was performed by following the manufacturer's recommended protocol from the "T-Pro nonliposome transfection reagent II (T-Pro NTRII)" transfection kit (T-Pro Biotechnology, JT97-N002). In brief, $1 \times 10^{5}$ cells/well were seeded for $24 \mathrm{~h}$, which was followed by the following transfection procedure. Plasmid DNA $(2 \mu \mathrm{L})$ or $6 \mu \mathrm{L}$ reagent II was mixed with Opti-MEM individually and then mixed together at RT for $20 \mathrm{~min}$. The mixture was added to individual wells containing cells for $5 \mathrm{hr}$. The cells were then washed with PBS and medium changed to $1 \%$ CDFBS for $19 \mathrm{hr}$. At $24 \mathrm{hr}$, luciferase activity was determined. The transfection efficiency was about $90 \%$. In parallel, the Renilla Luciferase Assay System (Promega Corporation, WI, USA) was used for reporter quantification. The results are presented as relative optic density ratios, namely, the ratio of the luciferase activity to the Renilla luciferase activity.

2.5. Western Blot Analysis. MCF-7 cells were cultured overnight at a density of $3 \times 10^{5}$ cells/well. The cells were then treated either with a CHE or withvehicle. Next the 
samples were homogenized using $400 \mu \mathrm{L}$ lysing buffer containing $150 \mathrm{mmol} / \mathrm{L} \mathrm{KCl,} 10 \mathrm{mM}$ Tris, $\mathrm{pH} 7.4$, 1\% Triton X100 , and protease inhibitor cocktail (Complete Mini, Roche, Mannheim, Germany). The protein concentration of each cell homogenates was determined as described previously [21]. Samples consisting of 30-50 $\mu \mathrm{g}$ of protein were separated on $10 \%$ SDS-polyacrylamide gels by electrophoresis and thereafter transferred to a PVDF membrane (Millipore, Bedford, MA, USA). The membrane was blocked with $5 \%$ bovine serum albumin and probed with specific primary antibodies, namely, anti-ER $\alpha$ (Stressgen Biotechnologies Inc., Victoria, BC, Canada), anti-pHER2/anti-tHER2 (IPVH00010, Millipore, Bedford, MA, USA), anti- $\alpha$-tubulin (AbFrontier, Seoul, Korea), and anti- $\beta$-actin (AbFrontier, Seoul, Korea). The immunoreactive bands were visualized using enhanced chemiluminescence detection reagents (Thermo Scientific, Bremen, Germany) and quantified by Multigauge software analysis (Fuji Photo Film Co., Ltd., Tokyo, Japan).

2.6. Statistical Analysis. Data are expressed as the mean \pm SEM. Differences between groups at each dose point were identified by one-way ANOVA, followed by Dunnett's post hoc test. A $P$ value $<0.05$ was considered statistically significant compared to vehicle or no treatment group.

\section{Results}

After assessing the cytotoxicity of the commonly used CHEs, which consist of twenty-two single herbs and six compound recipes, we chose a dose range when carrying out further experiments for each $\mathrm{CHE}$ where there was $\geq 80 \%$ cell survival (Table 2).

3.1. Effects of the CHEs on ERBB2-Luciferase Activity. At levels that caused little or no cytotoxicity, the effect of the CHEs on ERBB2-luciferase activity was determined by luciferase reporter assay. The results for the twenty-two herbs (Figure 1(a)) and six compound recipes (Figure 1(b)) are presented in Figure 1.

3.2. Effects of the CHEs on ESR1-Luciferase Activity. Similarly, the effect of the CHEs on ESR1-luciferase activity was also determined by luciferase reporter assay. The results for the twenty-two herbs (Figure 2(a)) and six compound recipes (Figure 2(b)) are presented in Figure 2.

Since the nature and characteristics of the Chinese herbs studied here are quite different, the CHEs were categorized into four groups, namely, Qi-supplying herbs, bloodregulating herbs, heat-clearing herbs, and Yin-nourishing herbs. Furthermore, the herbs that induced an increase in ERBB2 and ESR1 luciferase activity, after normalization against the vehicle control, were grouped into three quantitative categories, namely $\leq 1.5,1.5-2.0$, and $\geq 2.0$. The effects of the Qi-supplying and blood-regulating herbs on ERBB2 and ESR1 luciferase activity are presented in Table 3, while the effects of the heat-clearing and Yin-nourishing herbs are presented in Table 4 . The effects of the compound recipes on $E R B B 2$ and ESR1 luciferase activity are presented in Table 5.
3.3. Effects of the CHEs on ER $\alpha$ and HER2 Protein Expression. In order to validate the results obtained from luciferase report assay, the effects of some CHEs on ER $\alpha$ and HER2 protein expression were analyzed by Western blotting (Figure 3).

Firstly, the effect of Ligusticum chuanxiong extract on ER $\alpha$ and HER2 protein expression was explored. Since the reduced form of Suan-Zao-Ren-Tang (r-SZRT) is composed of the same herbs as Suan-Zao-Ren-Tang except for Ligusticum chuanxiong which is missing, the effects of SZRT, r-SZRT, and Ligusticum chuanxiong on the protein expression levels of the HER 2 and $\mathrm{ER} \alpha$ were compared. The results showed that there was greater induction of pHER2 and $\mathrm{ER} \alpha$ protein expression by Ligusticum chuanxiong alone compared to SZRT and rSZRT (Figure 4).

Since ER $\alpha$ and HER2 play important roles in promoting the growth of breast cancer cells, cell proliferation was also evaluated after treatment of Ligusticum chuanxiong extract with or without exogenous estrogen. The results showed that cotreatment of E2 $\left(10^{-9} \mathrm{M}\right)$ and Ligusticum chuanxiong extract $(1 \mu \mathrm{g} / \mathrm{mL})$ stimulated the cell growth of MCF-7 cells, compared to E2 $\left(10^{-9} \mathrm{M}\right)$ alone or Ligusticum chuanxiong extract $(1 \mu \mathrm{g} / \mathrm{mL})$ alone (Figure 5$)$. These findings suggest that Ligusticum chuanxiong synergistically increases the effect of estrogen on MCF-7 cell proliferation.

\section{Discussion}

In this study, we have established an in vitro screening system that allows us to investigate the effects of commonly used Chinese herbs on ERBB2 and ESR1 gene expression. To our knowledge, we are the first to conduct such a study in order to provide important information that will affect clinical practice and the treatment of patients with receptor $(+)$ breast cancer.

There is a consensus that the contamination with lipopolysaccharide (LPS) during herb extraction may influence the interpretation for drug effect data. Thus, pretreatment of the cultured cells with polymyxin $\mathrm{B}(1 \mu \mathrm{g} / \mathrm{mL})$ is mandatory in order to avoid the possibility of LPS affecting the results [22]. In addition, charcoal-dextran stripped (CD) fetal bovine serum in phenol red-free medium has been commonly used previously in estrogen-sensitive culture systems in order to avoid the effects of exogenous estrogen [17]. Furthermore, the plasmids containing ERBB2-promoter region and the ESR1-promotor region with the luciferase gene were validated by direct sequencing and matched against public databases.

Previous studies have demonstrated that some Chinese herbs are able to modulate HER2 expression in vitro. For examples, black cohosh, Shiraia bambusicola, and honokiol have been shown to suppress the growth of breast cancer cells on the molecular level via an inhibition of HER2 expression [23-25]. In addition, celastrol, 11,11' -dideoxy-verticillin ( $\mathrm{ZH}-$ 4B) (Shiraia bambusicola), and houttuyninum have been found to suppress $E R B B 2$ gene expression in animal models [26-28]. In contrast, our previous studies have demonstrated that Si-Wu-Tang and its constituent (ferulic acid) are able to upregulate HER2 signaling [17, 20]. 

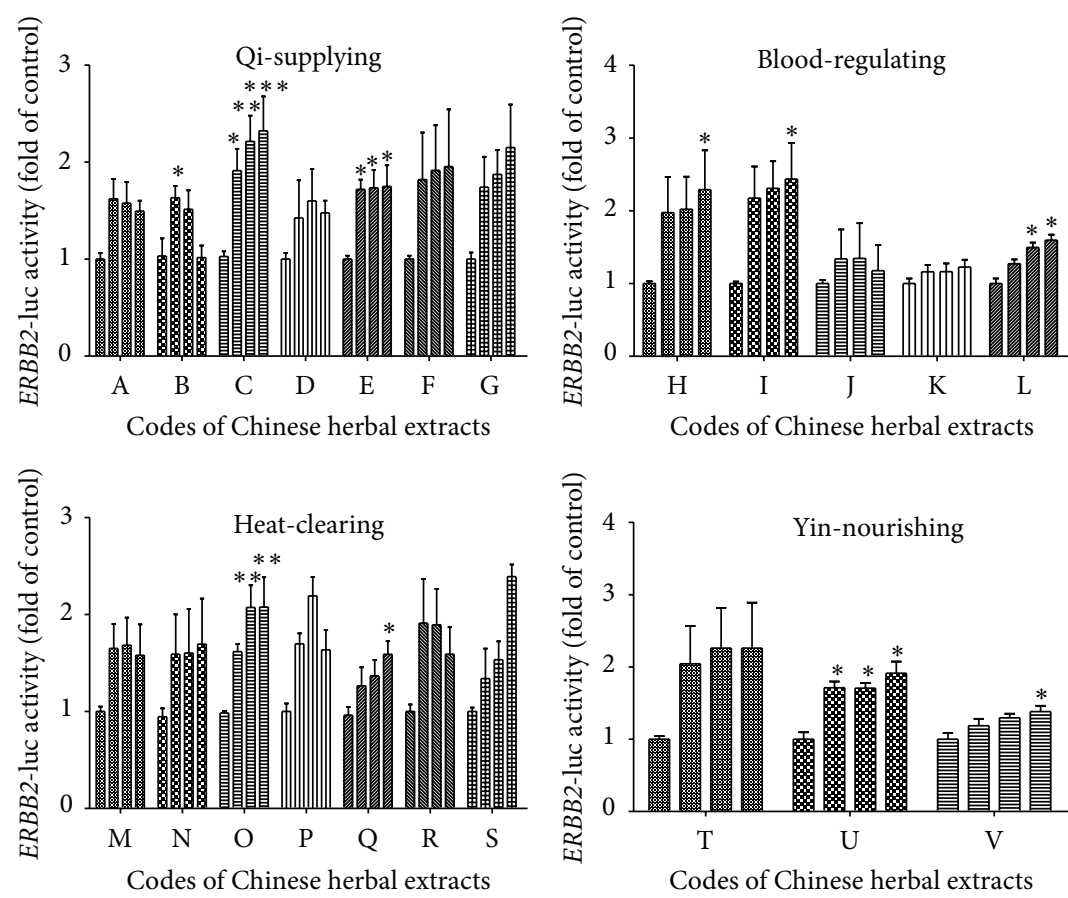

(a)
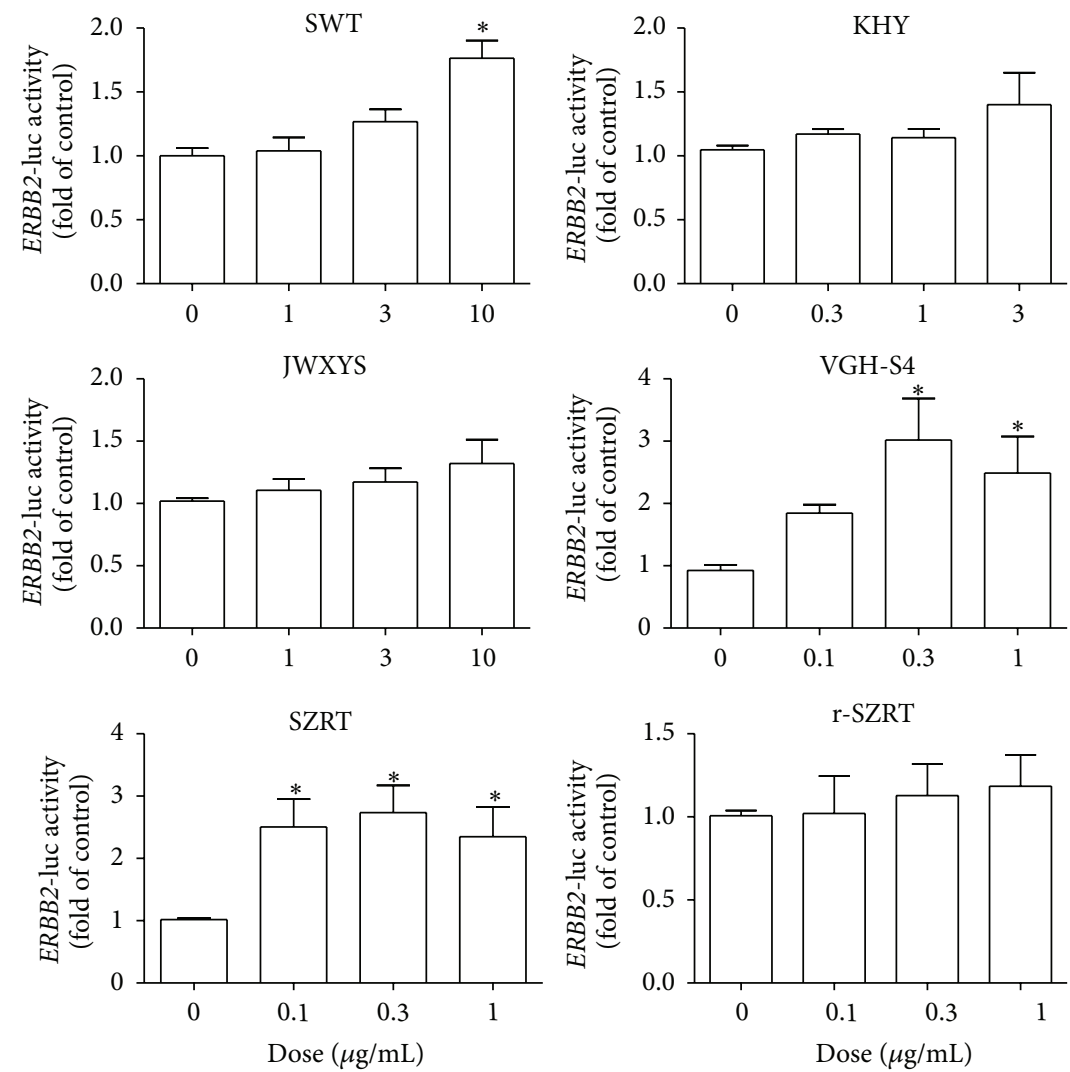

(b)

FIGURE 1: Effects of commonly used Chinese herbal extracts on ERBB2-luciferase activity using the MCF-7 cell line. The MCF-7 line $(1 \times$ $10^{5}$ cells/well) was seeded for $24 \mathrm{~h}$, followed by transfection with the ERBB2-luciferase plasmid and treatment individually with twenty-two single herbal extracts (a) and six compound recipes (b) as described in Section 2. The codes for the twenty-two herbs (from A to V) are described in Section 2. Data are presented as the relative optic density ratio, namely, the ratio of luciferase activity to Renilla luciferase ratio and were analyzed using four to six independent experiments. An asterisk indicates a $P$ value $<0.05$ versus the vehicle group by one-way ANOVA. 

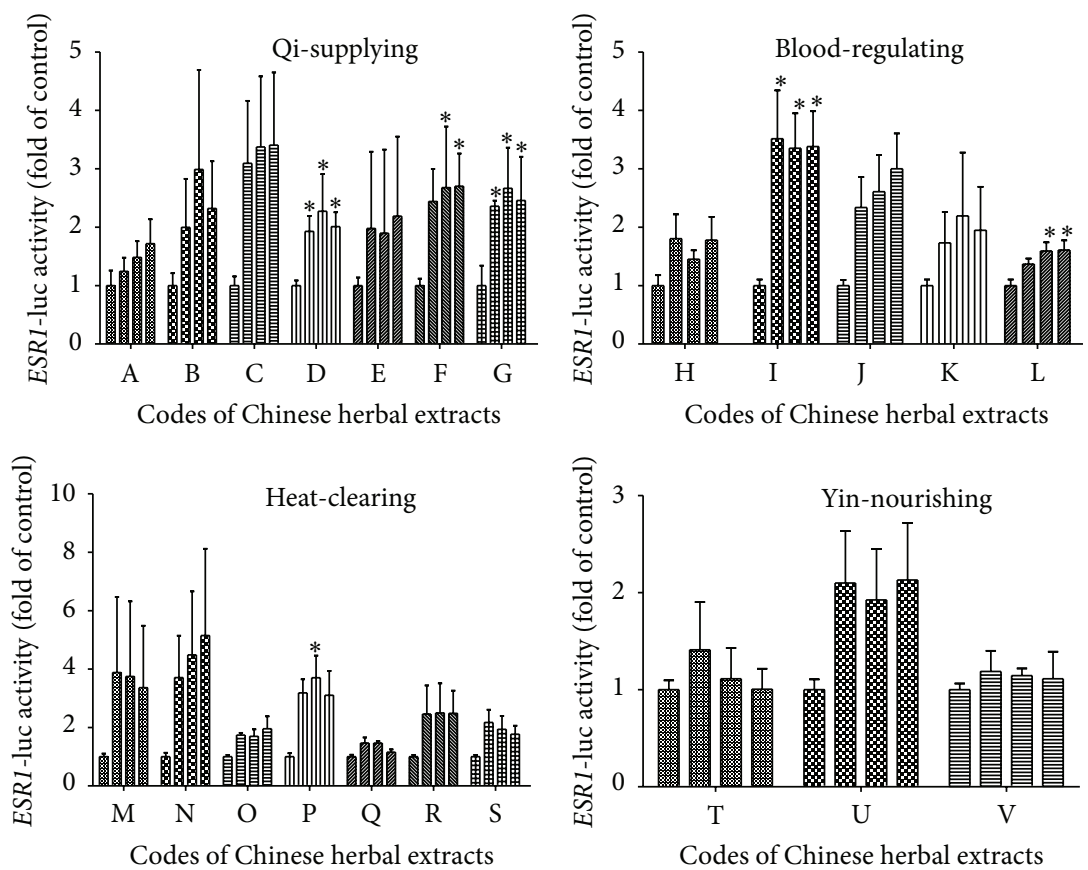

(a)
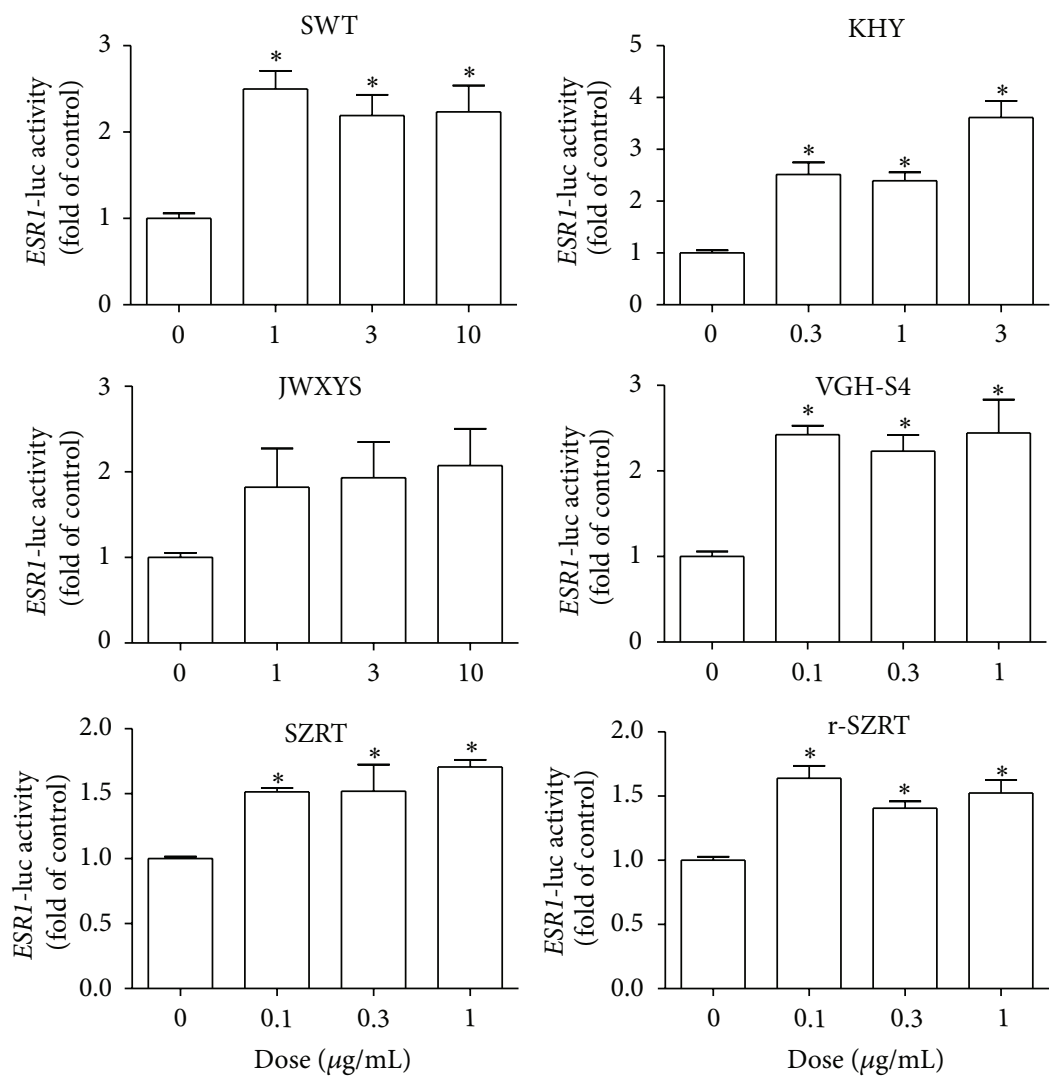

(b)

FIGURE 2: Effects of commonly used Chinese herbal extracts on ESR1-luciferase activity using the MCF-7 cell line. The MCF-7 line $\left(1 \times 10^{5}\right.$ cells/well) was seeded for $24 \mathrm{~h}$, followed by transfection with the ESR1-luciferase plasmid and treated with twenty-two single herbal extracts (a) and six compound recipes (b) as described in Section 2. The codes of twenty-two herbs (from A to V) are described in Section 2. Data are presented as the relative optic density ratio, namely, the ratio of luciferase activity to Renilla luciferase ratio and were analyzed using four to six independent experiments. An asterisk indicates a $P$ value $<0.05$ versus the vehicle group by one-way ANOVA. 
TABLE 2: Effects of commonly used Chinese herbs on cytotoxicity.

\begin{tabular}{|c|c|c|c|}
\hline & Scientific name & Dose range & Cell survival $\leqq 80 \%$ \\
\hline \multirow{7}{*}{ Qi-supplying } & Astragalus membranaceus & $0.1 \sim 10 \mu \mathrm{g} / \mathrm{mL}$ & $(-)$ \\
\hline & Atractylodes macrocephala & $0.1 \sim 10 \mu \mathrm{g} / \mathrm{mL}$ & $(-)$ \\
\hline & Poria cocos & $0.1 \sim 10 \mu \mathrm{g} / \mathrm{mL}$ & $(-)$ \\
\hline & Glycyrrhiza uralensis & $0.1 \sim 10 \mu \mathrm{g} / \mathrm{mL}$ & $(-)$ \\
\hline & Agastache rugosa & $0.1 \sim 10 \mu \mathrm{g} / \mathrm{mL}$ & $(-)$ \\
\hline & Codonopsis pilosula & $0.1 \sim 10 \mu \mathrm{g} / \mathrm{mL}$ & $(-)$ \\
\hline & Zingiber officinale & $0.1 \sim 10 \mu \mathrm{g} / \mathrm{mL}$ & $(-)$ \\
\hline \multirow{5}{*}{ Blood-regulating } & Angelica sinensis & $0.1 \sim 10 \mu \mathrm{g} / \mathrm{mL}$ & $3 \mu \mathrm{g} / \mathrm{mL}^{*}$ \\
\hline & Ligusticum chuanxiong & $0.1 \sim 10 \mu \mathrm{g} / \mathrm{mL}$ & $(-)$ \\
\hline & Ziziphus jujuba & $0.1 \sim 10 \mu \mathrm{g} / \mathrm{mL}$ & $(-)$ \\
\hline & Millettia dielsiana & $0.1 \sim 10 \mu \mathrm{g} / \mathrm{mL}$ & $(-)$ \\
\hline & Curcuma phaeocaulis & $0.1 \sim 10 \mu \mathrm{g} / \mathrm{mL}$ & $(-)$ \\
\hline \multirow{7}{*}{ Heat-clearing } & Folium nelumbinis & $0.1 \sim 10 \mu \mathrm{g} / \mathrm{mL}$ & $(-)$ \\
\hline & Bupleurum chinense & $0.1 \sim 10 \mu \mathrm{g} / \mathrm{mL}$ & $(-)$ \\
\hline & Mentha piperita & $0.1 \sim 10 \mu \mathrm{g} / \mathrm{mL}$ & $(-)$ \\
\hline & Gardenia jasminoides & $0.1 \sim 10 \mu \mathrm{g} / \mathrm{mL}$ & $(-)$ \\
\hline & Paeonia suffruticosa & $0.1 \sim 10 \mu \mathrm{g} / \mathrm{mL}$ & $(-)$ \\
\hline & Taraxacum mongolicum & $0.1 \sim 10 \mu \mathrm{g} / \mathrm{mL}$ & $(-)$ \\
\hline & Anemarrhena asphodeloides & $0.1 \sim 10 \mu \mathrm{g} / \mathrm{mL}$ & $(-)$ \\
\hline \multirow{3}{*}{ Yin-nourishing } & Paeonia lactiflora & $0.1 \sim 10 \mu \mathrm{g} / \mathrm{mL}$ & $10 \mu \mathrm{g} / \mathrm{mL}^{*}$ \\
\hline & Rehmannia glutinosa & $0.1 \sim 10 \mu \mathrm{g} / \mathrm{mL}$ & $(-)$ \\
\hline & Ligustrum lucidum & $0.1 \sim 10 \mu \mathrm{g} / \mathrm{mL}$ & $(-)$ \\
\hline \multirow{6}{*}{ Compound recipes and abbreviations } & Si-Wu-Tang & $0.1 \sim 10 \mu \mathrm{g} / \mathrm{mL}$ & $(-)$ \\
\hline & Jia-Wei-Xiao-Yao-San & $0.1 \sim 10 \mu \mathrm{g} / \mathrm{mL}$ & $(-)$ \\
\hline & Suan-Zsao-Ren-Tang & $0.1 \sim 10 \mu \mathrm{g} / \mathrm{mL}$ & $(-)$ \\
\hline & Reduced formula of Suan-Zsao-Ren-Tang & $0.1 \sim 10 \mu \mathrm{g} / \mathrm{mL}$ & $(-)$ \\
\hline & K’uan-Hsin-Yin & $0.1 \sim 10 \mu \mathrm{g} / \mathrm{mL}$ & $(-)$ \\
\hline & VGH-S4 & $0.1 \sim 10 \mu \mathrm{g} / \mathrm{mL}$ & $(-)$ \\
\hline
\end{tabular}

Cell cytotoxicity was determined by MTT assay as described in the Methods section. VGH-S4 is a compound recipe commonly used in Taipei Veterans General Hospital.

${ }^{*} P<0.05$ versus vehicle group $(n \geq 4 \sim 6)$.

TABLE 3: Effects of Qi-supplying and Blood-regulating herbs on ERBB2 and ESR1 gene expression.

\begin{tabular}{|c|c|c|c|c|c|c|c|c|c|}
\hline \multirow{2}{*}{ Nature } & \multirow{2}{*}{ Scientific names } & \multirow{2}{*}{ Code } & \multirow{2}{*}{ Dose range $(\mu \mathrm{g} / \mathrm{mL})$} & \multicolumn{3}{|c|}{$E R B B 2$ (fold of control) } & \multicolumn{3}{|c|}{ ESR1 (fold of control) } \\
\hline & & & & $\leqq 1.5$ & $1.5-2$ & $\geqq 2$ & $\leqq 1.5$ & $1.5-2$ & $\geqq 2$ \\
\hline \multirow{7}{*}{ Qi-supplying } & Astragalus membranaceus & A & $0.3,1,3$ & & & & & \multirow{7}{*}{0.1} & \\
\hline & Atractylodes macrocephala & $\mathrm{B}$ & $1,3,10$ & & $1^{*}$ & & & & \\
\hline & Poria cocos & $\mathrm{C}$ & $0.3,1,3$ & & 0.3 & 1,3 & & & \\
\hline & Glycyrrhiza uralensis & $\mathrm{D}$ & $0.1,0.3,1$ & & & & & & $0.3,1$ \\
\hline & Agastache rugosa & $\mathrm{E}$ & $0.3,1,3$ & & $0.3,1,3$ & & & & \\
\hline & Codonopsis pilosula & $\mathrm{F}$ & $1,3,10$ & & & & & & 3,10 \\
\hline & Zingiber officinale & G & $0.1,0.3,1$ & & & & & & $0.1,0.3,1$ \\
\hline \multirow{5}{*}{ Blood-regulating } & Angelica sinensis & $\mathrm{H}$ & $0.1,0.3,1$ & & 1 & \multirow{4}{*}{1} & & & \\
\hline & Ligusticum chuanxiong & I & $0.1,0.3,1$ & & & & & & $0.1,0.3,1$ \\
\hline & Ziziphus jujuba & $\mathrm{J}$ & $0.3,1,3$ & & & & & & \\
\hline & Mucuna birdwoodiana & $\mathrm{K}$ & $0.3,1,3$ & & & & & & \\
\hline & Curcuma phaeocaulis & $\mathrm{L}$ & $0.3,1,3$ & & 3 & & & 1,3 & \\
\hline
\end{tabular}

ERBB2 and ESR1 gene expression was determined by luciferase reporter assay as described in the Methods section.

${ }^{*}$ Number indicates the dose that has effect with statistically significant difference $(P<0.05)$ versus vehicle group $(n \geq 6)$. 

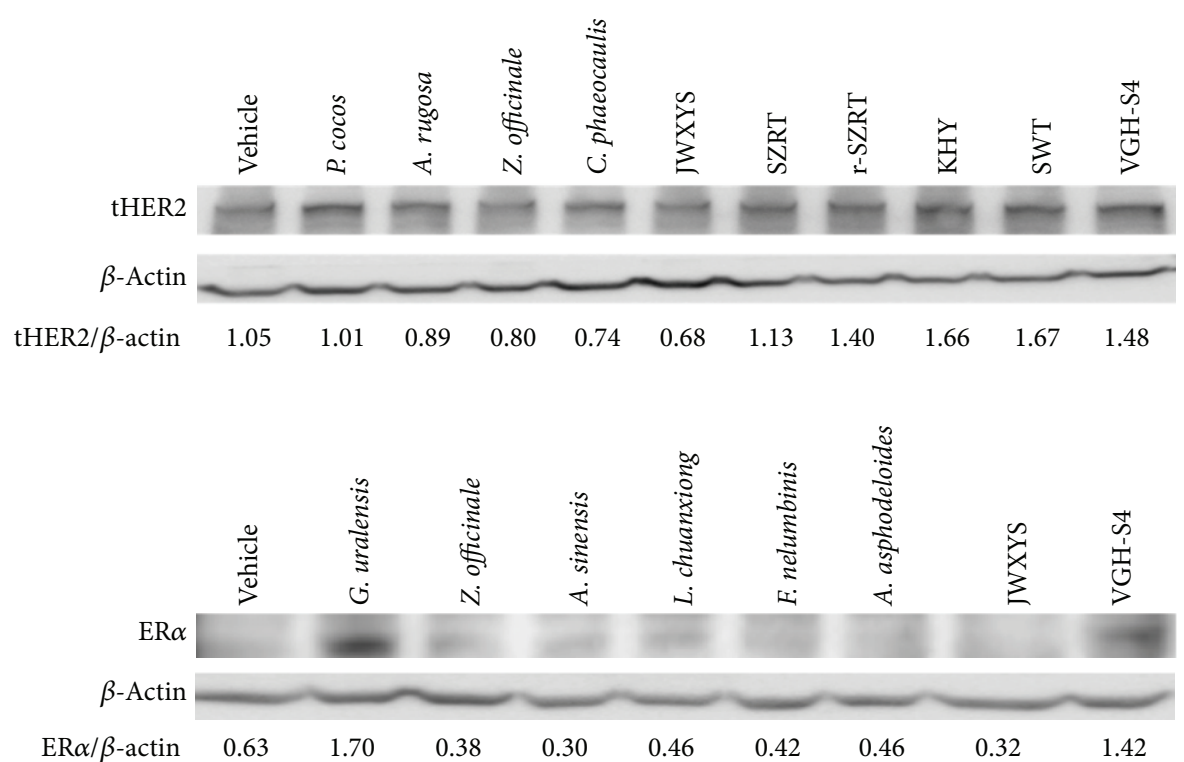

FIGURE 3: Effects of Chinese herbal extracts on HER2 and ER $\alpha$ protein expression using the MCF-7 cell line. The MCF-7 line $\left(1 \times 10^{6}\right.$ cells) was seeded for $24 \mathrm{~h}$ and changed to $1 \%$ CDFBS medium for 4 days and then treated with each Chinese herbal extract individually for another $24 \mathrm{~h}$. Then the cells were treated with lysing buffer and analyzed by Western blotting using anti-HER2 antibodies (a) and anti-ER $\alpha$ antibody (b) as described in Section 2. The OD ratio indicates the relative optic density ratio using $\beta$-actin as the control.
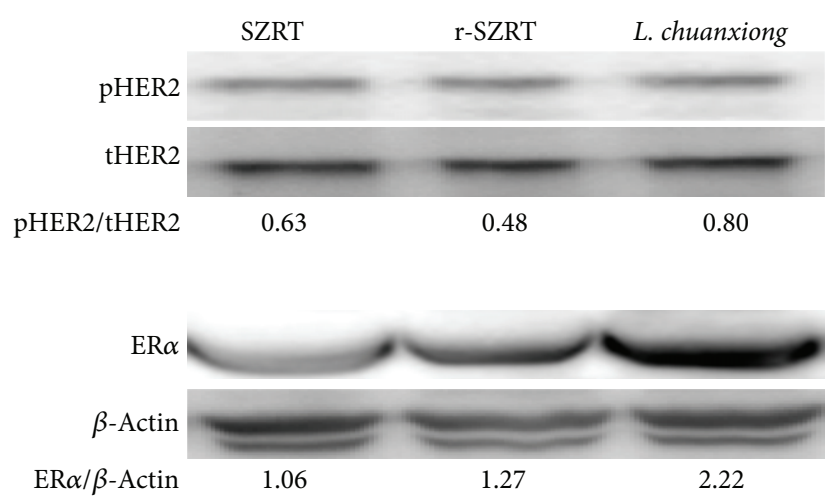

FIGURE 4: Effects of Ligusticum chuanxiong extract on ER $\alpha$ and HER2 protein expression using the MCF-7 cell line. The MCF-7 line $(1 \times$ $10^{6}$ cells) was seeded for $24 \mathrm{~h}$ and changed to $1 \%$ CDFBS medium for 4 days and then treated with Suan-Zao-Ren-Tang (SZRT), the reduced form of Suan-Zao-Ren-Tang (r-SZRT) or Ligusticum chuanxiong extracts, for another $24 \mathrm{hr}$. Then the cells were treated with lysing buffer and analyzed by Western blotting using anti-HER2 antibodies (a) and anti-ER $\alpha$ antibody (b) as described in the Methods section. The OD ratio indicates the relative optic density ratio using $\beta$-actin as the control.

Estrogen receptor (ER), which is encoded by the ESR gene, is a ligand-activated transcription factor essential for sexual development, reproductive functioning, and bone formation. Since the status of ER in breast cancer cells plays an important prognostic role, therapies that antagonize the ER-related signaling, such as tamoxifen, remain important adjuvant treatments after breast cancer surgery [6-8]. Recently, several organisms, such as Ganoderma lucidum and Scutellaria baicalensis, have been reported to suppress ER expression in vitro [29, 30]; while Salvia miltiorrhiza was found to activate AKT and inhibit apoptosis in cardiomyoblasts via the estrogen receptor [31]. It is well known that hormone therapies may cause adverse effects on patients, such as insomnia, hot flushes, cancer-related fatigue, and joint pain among breast cancer patients. For this reason, the use of complementary and alternative medicine (CAM) has become popular among patients receiving hormonal therapy $[32,33]$. For examples, estrogenic botanical supplements and Chinese herbal remedies are commonly used by breast cancer survivors to relieve their discomfort during hormonal therapy $[16,18,34]$. Recently, herb-drug interaction has become an important issue when treating receptor $(+)$ breast cancer patients.

With regard to functional validation of the present results, our previous in vitro studies [17] have shown that $\mathrm{Si}-\mathrm{Wu}$ Tang (SWT) not only is able to upregulate the HER2 and ER $\alpha$ expression in MCF-7 cells but also stimulates the cell proliferation in BT474 (ER+, HER-2 high), MDAMB231 (ER-, HER-2 
TABLE 4: Effects of Heat-clearing and Yin-nourishing herbs on ERBB2 and ESR1 gene expression.

\begin{tabular}{|c|c|c|c|c|c|c|c|c|c|}
\hline \multirow{2}{*}{ Nature } & \multirow{2}{*}{ Scientific Names } & \multirow{2}{*}{ Code } & \multirow{2}{*}{ Dose range $(\mu \mathrm{g} / \mathrm{mL})$} & \multicolumn{3}{|c|}{$E R B B 2$ (fold of control) } & \multicolumn{3}{|c|}{ ESR1 (fold of control) } \\
\hline & & & & $\leqq 1.5$ & $1.5-2$ & $\geqq 2$ & $\leqq 1.5$ & $1.5-2$ & $\geqq 2$ \\
\hline \multirow{7}{*}{ Heat-clearing } & Folium nelumbinis & M & $0.3,1,3$ & & & & & & \\
\hline & Bupleurum chinense & $\mathrm{N}$ & $1,3,10$ & & & & & & \\
\hline & Mentha piperita & $\mathrm{O}$ & $1,3,10$ & & & $3^{*}, 10$ & & & \\
\hline & Gardenia jasminoides & $\mathrm{P}$ & $0.3,1,3$ & & & & & & 1 \\
\hline & Paeonia suffruticosa & Q & $0.1,0.3,1$ & & 1 & & & & \\
\hline & Anemarrhena asphodeloides & $\mathrm{R}$ & $0.03,0.1,0.3$ & & & & & & \\
\hline & Taraxacum mongolicum & S & $0.3,1,3$ & & & & & & \\
\hline \multirow{3}{*}{ Yin-nourishing } & Paeonia lactiflora & $\mathrm{T}$ & $0.3,1,3$ & & & & & & \\
\hline & Rehmannia glutinosa & $\mathrm{U}$ & $0.1,0.3,1$ & & & & & & \\
\hline & Ligustrum lucidum & $\mathrm{V}$ & $0.3,1,3$ & & $0.3,1,3$ & & & & \\
\hline
\end{tabular}

ERBB2 and ESR1 gene expression was determined by luciferase reporter assay as described in the Methods section.

${ }^{*}$ Number indicates the dose that has effect with statistically significant difference $(P<0.05)$ versus vehicle group $(n \geq 6)$.

TABLE 5: Effects of Chinese compound recipes on ERBB2 and ESR1 gene expression.

\begin{tabular}{|c|c|c|c|c|c|c|c|c|}
\hline \multirow{2}{*}{ Names } & \multirow{2}{*}{ Abbreviation } & \multirow{2}{*}{ Dose range $(\mu \mathrm{g} / \mathrm{mL})$} & \multicolumn{3}{|c|}{ ERBB2 (fold of control) } & \multicolumn{3}{|c|}{ ESR1 (fold of control) } \\
\hline & & & $\leqq 1.5$ & $1.5-2$ & $\geqq 2$ & $\leqq 1.5$ & $1.5-2$ & $\geqq 2$ \\
\hline Si-Wu-Tang & SWT & $1,3,10$ & & $10^{*}$ & & & & $1,3,10$ \\
\hline Jia-Wei-Xiao-Yao-San & JWXYS & $1,3,10$ & & & & & & \\
\hline Suan-Zsao-Ren-Tang & SZRT & $0.1,0.3,1$ & & & $0.1,0.3,1$ & & $0.1,0.3,1$ & \\
\hline Reduced formula of Suan-Zsao-Ren-Tang ${ }^{\#}$ & r-SZRT & $0.1,0.3,1$ & & & & 0.3 & $0.1,1$ & \\
\hline Kuan-Shin-Yin & KHY & $0.3,1,3$ & & & & & & $0.3,1,3$ \\
\hline VGH-S4 & VGH-S4 & $0.1,0.3,1$ & & & $0.3,1$ & & & $0.1,0.3,1$ \\
\hline
\end{tabular}

ERBB2 and ESR1 gene expression was determined by luciferase reporter assay as described in the Methods section. VGH-S4 is a compound recipe commonly used in Taipei Veterans General Hospital.

${ }^{\#}$ Reduced formula of Suan-Zsao-Ren-Tang ( $r$-SZRT) is composed of those materials in Suan-Zsao-Ren-Tang except for Ligusticum chuanxiong which is absent.

${ }^{*}$ Number indicates the dose that has effect with statistically significant difference $(P<0.05)$ versus vehicle group $(n \geq 6)$.

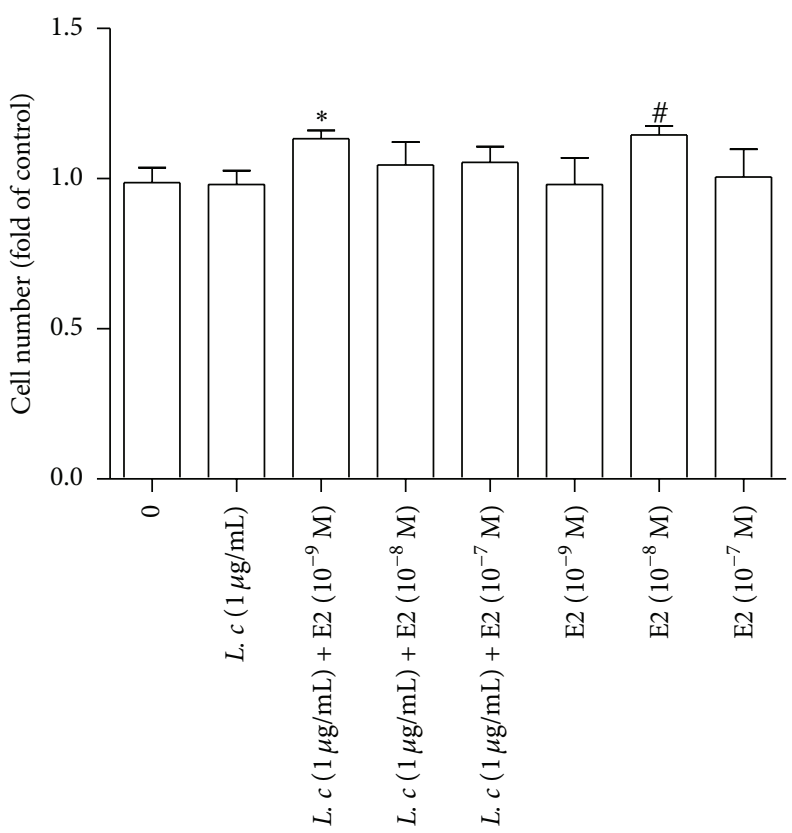

FIGURE 5: Effects of combined treatment with Ligusticum chuanxiong and estrogen (E2) on the cell proliferation of MCF-7 cells. The MCF-7 line $\left(1 \times 10^{6}\right.$ cells) was seeded for $24 \mathrm{~h}$ and changed to $1 \%$ CDFBS medium for 4 days and then treated with Ligusticum chuanxiong extract $(1 \mu \mathrm{g} / \mathrm{mL})$ with or without exogenous estrogen E2 $\left(10^{-9} \sim 10^{-7} \mathrm{M}\right)$. This was followed by counting the cell numbers using the trypan blue exclusion method. Data are presented as folds relative to the control and were analyzed using six independent experiments. An asterisk indicates a $P$ value $<0.05$ versus vehicle group. 
low), and SKBR3 (ER-, HER-2 high) mammary duct cell lines. Besides, SWT reversed tamoxifen-induced antiproliferative effects in MCF-7 cells, both in vitro and in vivo; and SWT also reversed trastuzumab-induced antiproliferative activity in different properties of breast cancer HER2+ cell lines (SKBR-3 and BT-474) through increased phosphorylation of the cell cycle regulatory protein $\mathrm{p} 27$ (Kip1) and possibly of the antiapoptosis protein P38 [17, 19].

Jia-Wei-Xiao-Yao-San (JWXYS), which is composed of ten herbs, has been used by Chinese people for centuries and ranks as the first most common Chinese medicine decoction coprescribed with tamoxifen when breast cancer is treated by hormonal therapy $[18,35]$. It is of note that some of the herbs in JWXYS are able to upregulate ERBB2 and ESR1 gene expression, while JWXYS alone does not induce any significant change in the expression of the above-mentioned genes. We attribute this to the fact that there are drugdrug and drug-cell interactions between these components in JWXYS's composition. Similar but distinct results in terms of synergism were found for VGH-S4, a compound recipe composed of Curcuma phaeocaulis, Taraxacum mongolicum, Millettia dielsiana, and Mentha piperita. Our results showed that, among the four components, only Taraxacum mongolicum was able to significantly upregulate ERBB2 and ESR1 gene expression; nevertheless, VGH-S4 had a more potent ERBB2 and ESR1 induction effect than Taraxacum mongolicum alone, suggesting a positive synergistic effect on ERBB2 and ESR1 expression between the herbs in VGH-S4.

In summary, the results obtained from this study provide important information to both Western medical practitioners and TCM doctors who are treating breast cancer using hormonal or targeted therapy.

\section{Conflict of Interests}

The authors declare that there is no conflict of interests regarding the publication of this paper.

\section{Acknowledgments}

The luciferase reporter vectors, RDB no. 2839 and RDB no. 7528 , use in this study was deposited by Dr. Masatoshi Tagawa at Chiba Cancer Center and Gene Engineering Division of RIKEN BioResource Center, respectively. These two clones were provided by the RIKEN BRC through the National BioResource Project of the Ministry of Education, Culture, Sports, Science, and Technology (MEXT), Japan. This work was assisted by the Division of Experimental Surgery, Department of Surgery, Taipei Veterans General Hospital. This work was supported by Grants from Taipei Veterans General Hospital (V103C-022), Cheng-Hsin \& Yang-Ming Project (102F218C04), and Ministry of Health and Welfare Surcharge of Tobacco Products (MOHW103-TD-B-111-02).

\section{References}

[1] AIRTUM Working Group, E. Crocetti, and C. Buzzoni, "New incidence and mortality data. 2003-2005," Epidemiologia e
Prevenzione, vol. 33, no. 1-2, supplement 2, pp. el-e5, e5-26, 2009.

[2] R.O.C, "D.o.H. Bureau of Health Promotion," Annual Report, Department of Health, R.O.C, 2007.

[3] G. Viale, "The current state of breast cancer classification," Annals of Oncology, vol. 23, supplement 10, pp. x207-x210, 2012.

[4] S. Guiu, S. Michiels, F. André et al., "Molecular subclasses of breast cancer: how do we define them? The IMPAKT 2012 working group statement," Annals of Oncology, vol. 23, no. 12, pp. 2997-3006, 2012.

[5] L. A. Carey, C. M. Perou, C. A. Livasy et al., "Race, breast cancer subtypes, and survival in the Carolina Breast Cancer Study," Journal of the American Medical Association, vol. 295, no. 21, pp. 2492-2502, 2006.

[6] W. J. Lu, Z. Desta, and D. A. Flockhart, “Tamoxifen metabolites as active inhibitors of aromatase in the treatment of breast cancer," Breast Cancer Research and Treatment, vol. 131, no. 2, pp. 473-481, 2012.

[7] C. Criscitiello, D. Fumagalli, K. S. Saini, and S. Loi, “Tamoxifen in early-stage estrogen receptorpositive breast cancer: Overview of clinical use and molecular biomarkers for patient selection," OncoTargets and Therapy, vol. 4, pp. 1-11, 2011.

[8] Early Breast Cancer Trialists' Collaborative Group (EBCTCG), "Effects of chemotherapy and hormonal therapy for early breast cancer on recurrence and 15-year survival: an overview of the randomised trials," The Lancet, vol. 365, no. 9472, pp. 1687-1717, 2005.

[9] F. Montemurro and M. Aglietta, "Duration of trastuzumab for HER2-positive breast cancer," The Lancet Oncology, vol. 14, no. 8, pp. 678-679, 2013.

[10] S. M. Swain, S.-B. Kim, J. Cortés et al., "Pertuzumab, trastuzumab, and docetaxel for HER2-positive metastatic breast cancer (CLEOPATRA study): overall survival results from a randomised, double-blind, placebo-controlled, phase 3 study," The Lancet Oncology, vol. 14, no. 6, pp. 461-471, 2013.

[11] H. Takei, S. Ohsumi, K. Shimozuma et al., "Health-related quality of life, psychological distress, and adverse events in postmenopausal women with breast cancer who receive tamoxifen, exemestane, or anastrozole as adjuvant endocrine therapy: National Surgical Adjuvant Study of Breast Cancer 04 (N-SAS BC 04)," Breast Cancer Research and Treatment, vol. 133, no. 1, pp. 227-236, 2012.

[12] T. J. Powles, S. Ashley, A. Tidy, I. E. Smith, and M. Dowsett, "Twenty-year follow-up of the Royal Marsden randomized, double-blinded tamoxifen breast cancer prevention trial," Journal of the National Cancer Institute, vol. 99, no. 4, pp. 283-290, 2007.

[13] S. L'Espérance, S. Frenette, A. Dionne, and J.-Y. Dionne, "Pharmacological and non-hormonal treatment of hot flashes in breast cancer survivors: CEPO review and recommendations," Supportive Care in Cancer, vol. 21, no. 5, pp. 1461-1474, 2013.

[14] E. Ernst and B. R. Cassileth, "The prevalence of complementary/alternative medicine in cancer: a systematic review," Cancer, vol. 83, no. 4, pp. 777-782, 1998.

[15] H. S. Boon, F. Olatunde, and S. M. Zick, "Trends in complementary/alternative medicine use by breast cancer survivors: comparing survey data from 1998 and 2005," BMC Women's Health, vol. 7, article 4, 2007.

[16] Y.-H. Lin and J.-H. Chiu, "Use of Chinese medicine by women with breast cancer: a nationwide cross-sectional study in Taiwan," Complementary Therapies in Medicine, vol. 19, no. 3, pp. 137-143, 2011. 
[17] C. Chang, J. Chiu, and L. Tseng, "Si-Wu-Tang and its constituents promote mammary duct cell proliferation by upregulation of Her-2 signaling," Menopause, vol. 13, no. 6, pp. 967-976, 2006.

[18] J. N. Lai, C. T. Wu, and J. D. Wang, "Prescription pattern of chinese herbal products for breast cancer in taiwan: a population-based study," Evidence-Based Complementary and Alternative Medicine, vol. 2012, Article ID 891893, 7 pages, 2012.

[19] J.-L. Chen, J.-Y. Wang, Y.-F. Tsai et al., "In vivo and in vitro demonstration of herb-drug interference in human breast cancer cells treated with tamoxifen and trastuzumab," Menopause, vol. 20, no. 6, pp. 646-654, 2013.

[20] C. J. Chang, J. H. Chiu, L. M. Tseng et al., "Modulation of HER2 expression by ferulic acid on human breast cancer MCF7 cells," European Journal of Clinical Investigation, vol. 36, no. 8, pp. 588596, 2006.

[21] M. M. Bradford, "A rapid and sensitive method for the quantitation of microgram quantities of protein utilizing the principle of protein dye binding," Analytical Biochemistry, vol. 72, no. 1-2, pp. 248-254, 1976.

[22] L. S. Cardoso, M. I. Araujo, A. M. Góes, L. G. Pacífico, R. R. Oliveira, and S. C. Oliveira, "Polymyxin B as inhibitor of LPS contamination of Schistosoma mansoni recombinant proteins in human cytokine analysis," Microbial Cell Factories, vol. 6, article 1, 2007.

[23] L. S. Einbond, Y. Wen-Cai, K. He et al., "Growth inhibitory activity of extracts and compounds from Cimicifuga species on human breast cancer cells," Phytomedicine, vol. 15, no. 6-7, pp. 504-511, 2008.

[24] X.-N. Guo, L. Zhong, X.-H. Zhang et al., "Evaluation of active recombinant catalytic domain of human ErbB-2 tyrosine kinase, and suppression of activity by a naturally derived inhibitor, ZH-4B," Biochimica et Biophysica Acta-General Subjects, vol. 1673, no. 3, pp. 186-193, 2004.

[25] H. Liu, C. Zang, A. Emde et al., "Anti-tumor effect of honokiol alone and in combination with other anti-cancer agents in breast cancer," European Journal of Pharmacology, vol. 591, no. 1-3, pp. 43-51, 2008.

[26] S. M. Raja, R. J. Clubb, C. Ortega-Cava et al., "Anticancer activity of celastrol in combination with ErbB2-targeted therapeutics for treatment of ErbB2-overexpressing breast cancers," Cancer Biology and Therapy, vol. 11, no. 2, pp. 263-276, 2011.

[27] W. Yang, J.-H. Ju, M. J. Jeon, X. Han, and I. Shin, "Danshen (Salvia miltiorrhiza) extract inhibits proliferation of breast cancer cells via modulation of akt activity and p27 level," Phytotherapy Research, vol. 24, no. 2, pp. 198-204, 2010.

[28] N.-N. Zhou, J. Tang, W.-D. Chen et al., "Houttuyninum, an active constituent of Chinese herbal medicine, inhibits phosphorylation of HER2/neu receptor tyrosine kinase and the tumor growth of HER2/neu-overexpressing cancer cells," Life Sciences, vol. 90, no. 19-20, pp. 770-775, 2012.

[29] J. Jiang, V. Slivova, and D. Sliva, “Ganoderma lucidum inhibits proliferation of human breast cancer cells by down-regulation of estrogen receptor and NF- $\kappa$ B signaling," International Journal of Oncology, vol. 29, no. 3, pp. 695-703, 2006.

[30] H. Chung, Y.-M. Jung, D.-H. Shin et al., "Anticancer effects of wogonin in both estrogen receptor-positive and -negative human breast cancer cell lines in vitro and in nude mice xenografts," International Journal of Cancer, vol. 122, no. 4, pp. 816-822, 2008.

[31] Y.-S. Weng, W.-W. Kuo, Y.-M. Lin et al., "Danshen mediates through estrogen receptors to activate Akt and inhibit apoptosis effect of Leu27IGF-II-induced IGF-II receptor signaling activation in cardiomyoblasts," Food and Chemical Toxicology, vol. 56, pp. 28-39, 2013.

[32] D. M. Eisenberg, R. B. Davis, S. L. Ettner et al., "Trends in alternative medicine use in the United States, 1990-1997: results of a follow-up national survey," Journal of the American Medical Association, vol. 280, no. 18, pp. 1569-1575, 1998.

[33] A. Wanchai, J. M. Armer, and B. R. Stewart, "Complementary and alternative medicine use among women with breast cancer: a systematic review," Clinical Journal of Oncology Nursing, vol. 14, no. 4, pp. E45-E55, 2010.

[34] H. Ma, J. Sullivan-Halley, A. W. Smith et al., "Estrogenic botanical supplements, health-related quality of life, fatigue, and hormone-related symptoms in breast cancer survivors: a HEAL study report," BMC Complementary and Alternative Medicine, vol. 11, article 109, 2011.

[35] J. L. Chen, C. J. Chang, J. Y. Wang et al., "In vitro and in vivo effects of Jia-Wei-Xiao-Yao-San in human breast cancer MCF-7 cells treated with tamoxifen," Integrative Cancer Therapies, 2014. 


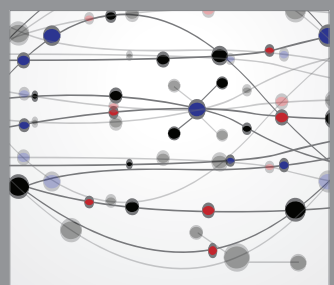

The Scientific World Journal
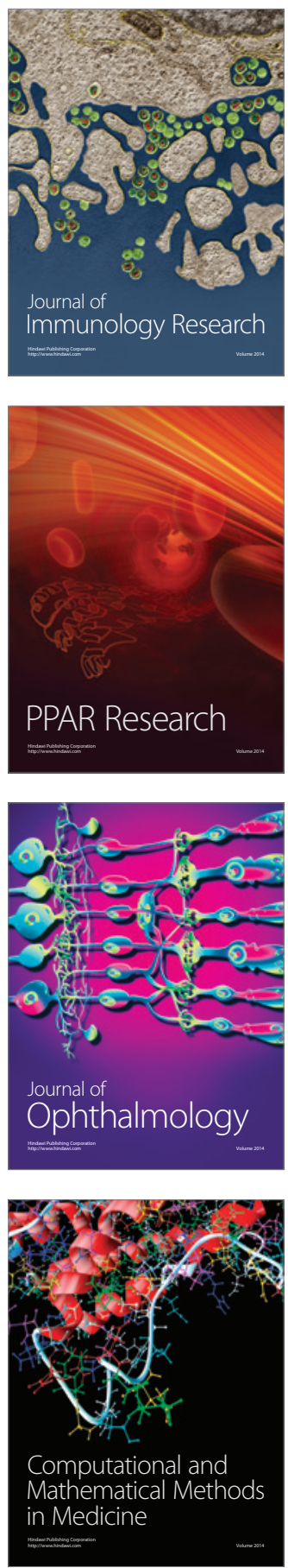

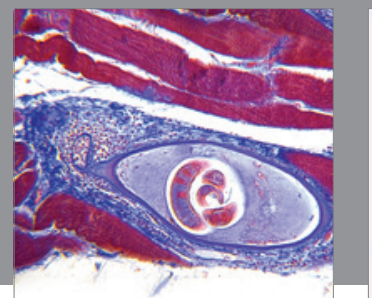

Gastroenterology

Research and Practice
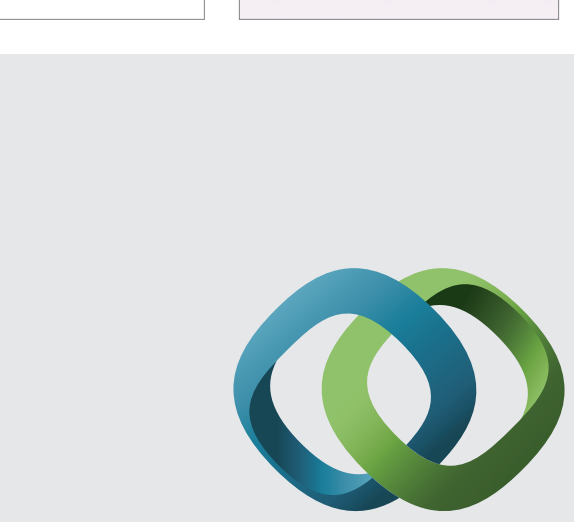

\section{Hindawi}

Submit your manuscripts at

http://www.hindawi.com
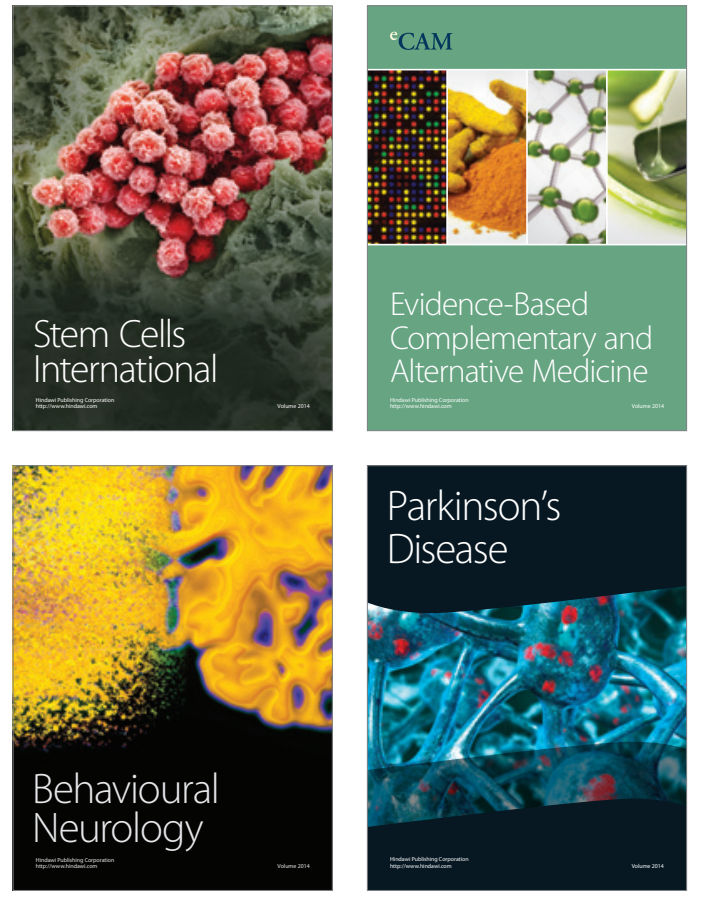
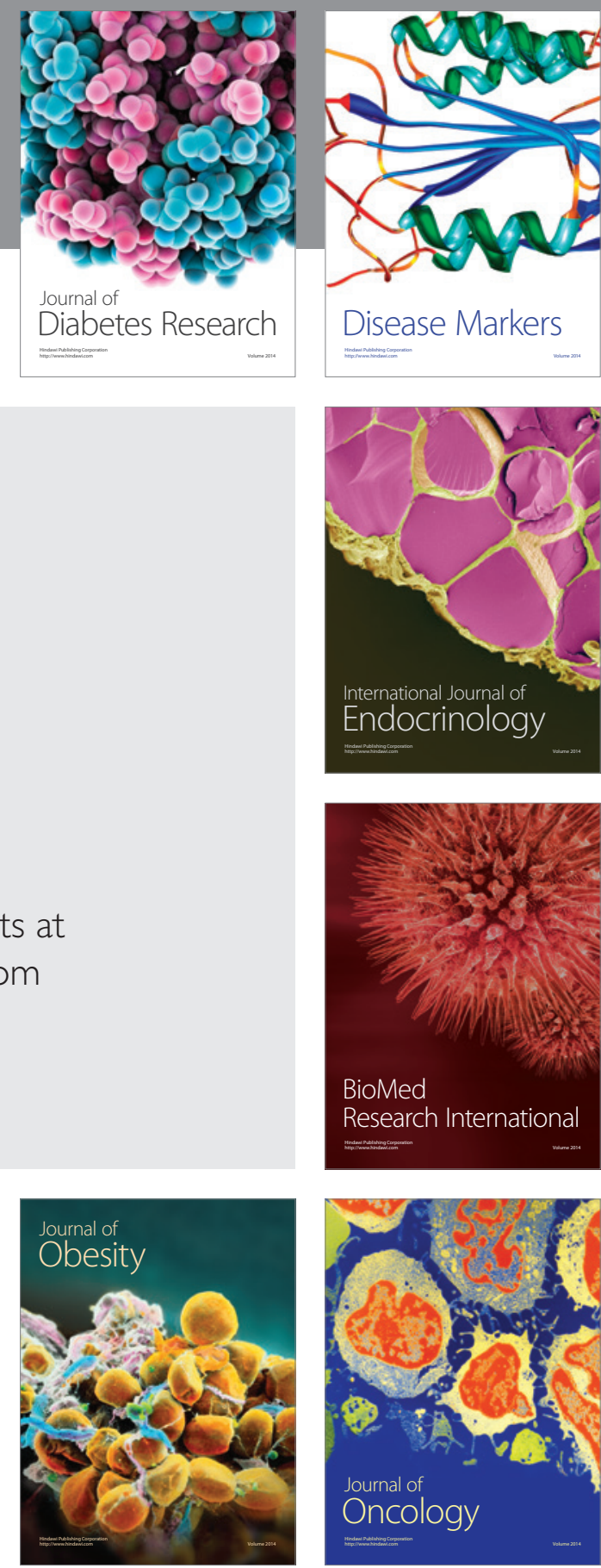

Disease Markers
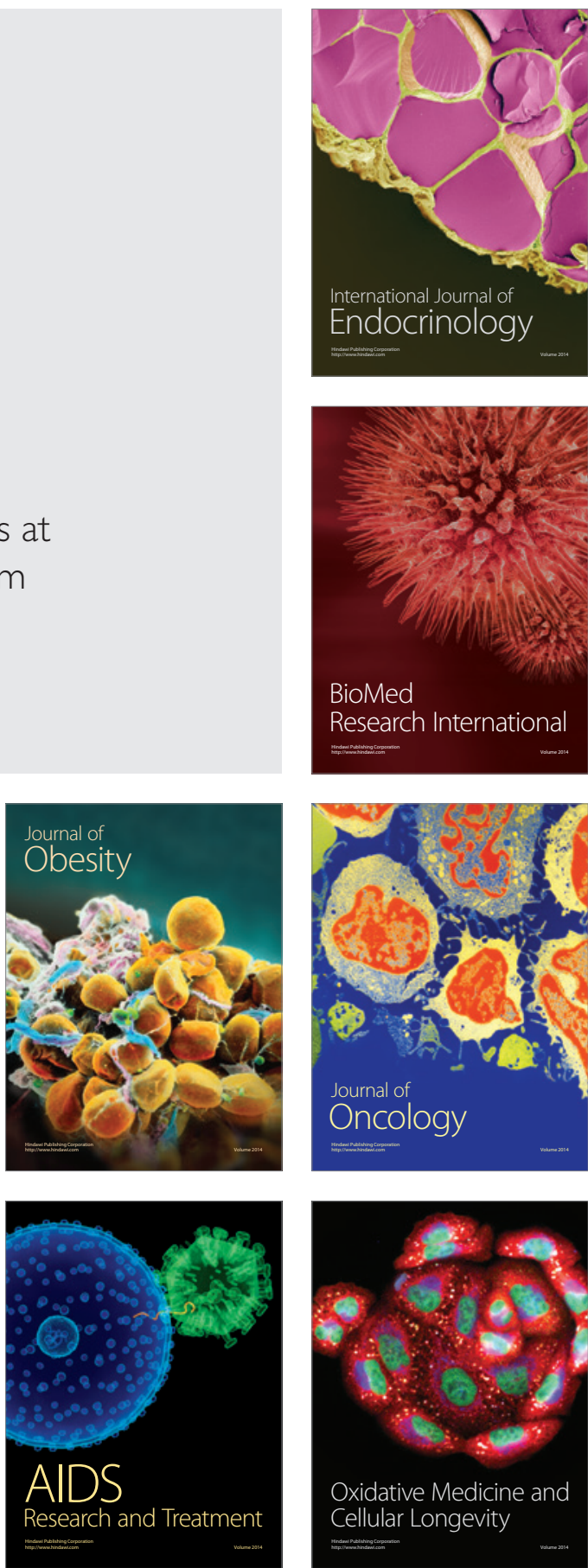